\title{
Computer Simulation of Heat Transfer in Regenerative Chambers of Self-preheating Hot Blast Stoves
}

\author{
Liangcai ZHONG, Quanxing LIU ${ }^{1)}$ and Wenzhong WANG \\ School of Materials and Metallurgy, Northeastern University, Shenyang, 110004 China. \\ 1) Iron-making Plant, Anshan Iron and Steel Co., Anshan, 114021 China.
}

(Received on September 24, 2003; accepted in final form on January 29, 2004)

\begin{abstract}
Heat transfer in chambers of self-preheating hot blast stoves in Anshan Iron and Steel Co., China, has been numerically simulated with a three-dimensional unsteady heat conduction equation and an energy conservation equation for fluid flowing through channels in the chambers. The blast temperature and air preheating temperature in the numerical simulation study are in good agreement with those in measurement. The numerical results show that hot blast temperature can reach $1200^{\circ} \mathrm{C}$ by using a self-preheating process and low calorific blast furnace gas under the studied operational conditions. Amount of heat exchange between the checkerwork and the fluids and usable heat increase in the middle and low parts of the chambers of the hot blast stoves due to the application of the self-preheating process.
\end{abstract}

KEY WORDS: self-preheating process; chamber of hot blast stove; heat transfer; numerical simulation.

\section{Introduction}

The hot blast stoves consist of a heat-storing matrix of solid material, often called "checkerwork". Heat is transferred between the matrix and the fluid, usually a gas, which passes through the channels in the matrix. In common processes for hot blast stoves, a cycle of operation consists of a heating period (or gas period) and a cooling period (or blast period). In the heating period, heat is transferred to the checkerwork from the gas with specified entrance temperature and specified flow rate. At the end of the heating period the hot gas is shut off and a reversal occurs. Then, the cooling period starts. A cold blast, usually air, with lower entrance temperature and specified flow rate passes through the channels of the checkerwork, in opposite direction of flow to that in the heating period. Throughout the cooling period, heat is transferred from the checkerwork to the gas. The cooling period is concluded by another reversal and the next heating period commences.

Modern blast furnace ironmaking needs higher blast temperature, especially in the case where pulverized coal injection technique is applied. Because higher calorie blast furnace gas is extremely deficient in China, it is very difficult to increase blast temperature to a higher level in hot blast stoves with the common processes. In order to solve the problem, a new technique, named self-preheating process, has been used in the stoves at Anshan Iron and Steel Co., China. In self-preheating process, a part of cold combustion air flows through the checkerwork of a hot blast stove after the end of blast period in the stove. The air is heated with the residual heat in the checkerwork and then directed to other stoves to take part in combustion. In this way, combustion temperature of low calorie gas is increased and higher blast temperature can be achieved. Hence, there are three periods, named gas period, blast period and preheating period, respectively, during a cycle of operation in a self-preheating hot blast stove.

In order to understand the performance of self-preheating process, numerical simulation of heat transfer in regenerative chambers of stoves was conducted in this research. In the 1930's, Hausen ${ }^{1,2)}$ put forward a mathematical model to describe heat transfer in hot blast stoves and analytically solved the model with eigenfunction method ${ }^{1)}$ and then with heat pole method. ${ }^{2}$ Butterfield $^{3)}$ and Willmott ${ }^{4,5)}$ used Hausen's model to numerically simulate the performance of heat transfer in hot blast stoves with computers. Three-dimensional unsteady heat conduction in checkerwork was considered in this work and numerically calculated by coupling it with heat exchange between checkerwork and fluid flowing through channels of the checkerwork.

\section{Governing Equations}

The checkerwork of hot blast stoves has many channels. Center-connecting lines among three neighboring channels form an equilateral triangle. The checkerwork inside the triangle consists of the numerical calculation domain. The physical model and co-ordinate system are shown in Fig. 1.

The differential equations used in the present work are based on the following assumptions: 1) The effect of the reversals can be neglected, because velocity of gas or blast flowing through the channels is so high that it takes only a short time for the gas or the blast passes from one end of the channels to the other, that is, the gas temperature transients which are associated with the residual gas in the hot blast stove being replaced by the gas flowing in the opposite 

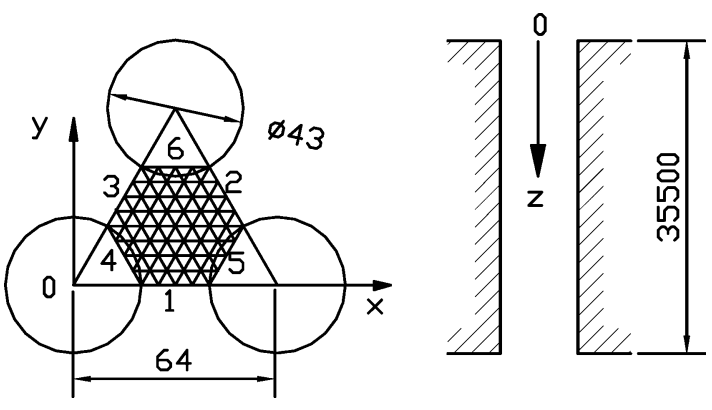

Fig. 1. Calculation domain and co-ordinate system.

direction at the reversal can be ignored. 2) The entrance gas temperatures in three periods remain constant. 3) Heat transfer between gas and checkerwork can be represented in terms of an overall heat transfer coefficient relating gas temperature to checkerwork surface temperature. Further the rate of heat transfer in the chekerwork at any height is represented by the time variation of the solid surface temperature of the channels in the checkerwork. 4) The transient term of the heat balance equation of gas flowing through the channels of the matrix is neglected by supposing that quasi-steady state for the gas phase is used and the steady state temperature distribution of the gas phase is achieved for each time step, due to the lower heat capacity of the gas phase per unit volume, $\rho_{\mathrm{f}} C_{\mathrm{pf}}$, relative to that of checkwork. 5) The heat-transfer coefficients and the thermal properties of heat storing checkerwork with the same material do not vary throughout a period and are identical at whole part of checkerwork with the same material in that period. 6) Heat exchange in each channel is the same. 7) The temperature fields at $z=0$ and $z=l$ are assumed to vary only with time for simplification because the area of checkwork inside the triangle is very small (the maximum distance in the area is $0.0425 \mathrm{~m}$ ) comparing to the height of channels $(35.5 \mathrm{~m})$, so that heat transfer in $z$ direction is less important than that perpendicular to $z$ direction.

The differential equation to describe the heat conduction in the checherwork can be written as:

$$
\rho C_{\mathrm{P}} \frac{\partial T}{\partial t}=\lambda\left(\frac{\partial^{2} T}{\partial x^{2}}+\frac{\partial^{2} T}{\partial y^{2}}+\frac{\partial^{2} T}{\partial z^{2}}\right) .
$$

Boundary conditions:

at boundaries 1, 2 and 3: $\frac{\partial T}{\partial n}=0$

at boundaries 4, 5 and 6: $\left.\quad T(x, y, z, t)\right|_{\mathrm{s}}=T_{\mathrm{s}}(z, t)$

at $z=0$ :

$$
T(x, y, 0, t)=T_{0}(t)
$$

at $z=l$ :

$$
T(x, y, l, t)=T_{l}(t) \text {. }
$$

Initial condition:

$$
T(x, y, z, 0)=T(x, y, z, H)
$$

Variations of temperature with time at dome of stoves and bottom of checkerwork were measured with two thermocouples, respectively, during operation of the stoves and the measurements were used as the boundary conditions (4) and (5).

From heat balance of gas passing through channels in a thin thickness $d z$, one can obtain the energy equation of the gas related to its average temperature:

$$
\frac{\partial T_{\mathrm{f}}}{\partial z}= \pm \frac{\alpha \pi d}{W_{\mathrm{i}} C_{\mathrm{P}, \mathrm{f}}}\left(T_{\mathrm{s}}-T_{\mathrm{f}}\right)
$$

where, the positive sign is for gas period and the negative for blast period and preheating period. Boundary conditions are:

$$
\begin{array}{lll}
\text { in gas period: } & T_{\mathrm{f}}(0, t)=T_{\mathrm{f}, 0}^{\mathrm{g}} & 0 \leq t \leq \tau_{\mathrm{g}} . \\
\text { in blast period: } & T_{\mathrm{f}}(l, t)=T_{\mathrm{f}, l}^{\mathrm{b}} & \tau_{\mathrm{g}} \leq t \leq \tau_{\mathrm{b}} \\
\text { in preheating period: } & T_{\mathrm{f}}(l, t)=T_{\mathrm{f}, l}^{\mathrm{p}} & \tau_{\mathrm{b}} \leq t \leq H
\end{array}
$$

The heat transfer coefficient $\alpha$ between flowing gas and checkerwork can be expressed as:

$$
\begin{array}{ll}
\alpha=\alpha_{\mathrm{c}}+\alpha_{\mathrm{r}} & \text { for gas period............................. } \\
\alpha=\alpha_{\mathrm{c}} & \text { for blast or preheat period. }
\end{array}
$$

The convective heat transfer coefficient can be calculated with the following equations ${ }^{6)}$ :

$$
\begin{aligned}
& \alpha_{\mathrm{c}}=0.687 u_{0}^{0.8} d^{-0.333}\left(T_{\mathrm{f}}+273\right)^{0.25} \\
& \text { for turbulence flow....... } \\
& \alpha_{\mathrm{c}}=\left(1.123+0.283 u_{0} d^{-0.4}\right)\left(T_{\mathrm{f}}+273\right)^{0.25} \\
& \text { for laminar flow } \ldots \ldots \ldots \ldots
\end{aligned}
$$

The radiative heat transfer coefficient is evaluated from the Stefan-Bolzmann law:

$$
\begin{aligned}
& \alpha_{\mathrm{r}}=\frac{q_{\mathrm{r}}}{T_{\mathrm{f}}-T_{\mathrm{s}}} \\
& q_{\mathrm{r}}=\varepsilon_{\mathrm{s}}^{\prime} C_{0}\left[\varepsilon\left(\frac{T_{\mathrm{f}}+273}{100}\right)^{4}-A\left(\frac{T_{\mathrm{s}}+273}{100}\right)^{4}\right] \ldots \ldots
\end{aligned}
$$

\section{Numerical Method}

Equilateral triangle network was used to divide the calculation domain of $x-y$ plane in checkerwork. Three straight lines were applied to substitute the circular boundaries of the domain, as shown in Fig. 1, for simplicity in numerical calculations. An iterative equation of temperature for one node in checkerwork was obtained by applying Eq. (1) to every node by a finite difference method. Iterative formulas of gas average temperature for nodes at $z$ direction were also achieved by using trapezoid formula. It was necessary to couple the heat conduction in checkerwork with the heat exchange between the checkerwork and gas flowing through the channels in numerical calculations. Heat flow rates must be continuous at the coupled boundary (gassolid interface), that is:

$$
-\left.\lambda \frac{\partial T}{\partial n}\right|_{\mathrm{s}}=\alpha\left(T_{\mathrm{f}}-T_{\mathrm{s}}\right)
$$

In a numerical calculation at a given time, the temperature profile $T_{\mathrm{s}}(z, t)$ was first assigned. Then the temperature fields of checkerwork and gas were numerically calculated and the heat flows at the coupled boundary for each area 
could be calculated from the two temperature profiles. Last, the criterion (17) was used to examine whether the temperature profile $T_{\mathrm{s}}(z, t)$ given before was correct or not. If the heat flow rates were not continuous, the coupled boundary temperature field would be revised and the above calculation procedure would be repeated until the Eq. (17) was met. Because of the cycle operation of a hot blast stove, the temperature profile in checkerwork at the beginning of a cycle should be the same as that at the end of the cycle (Eq.

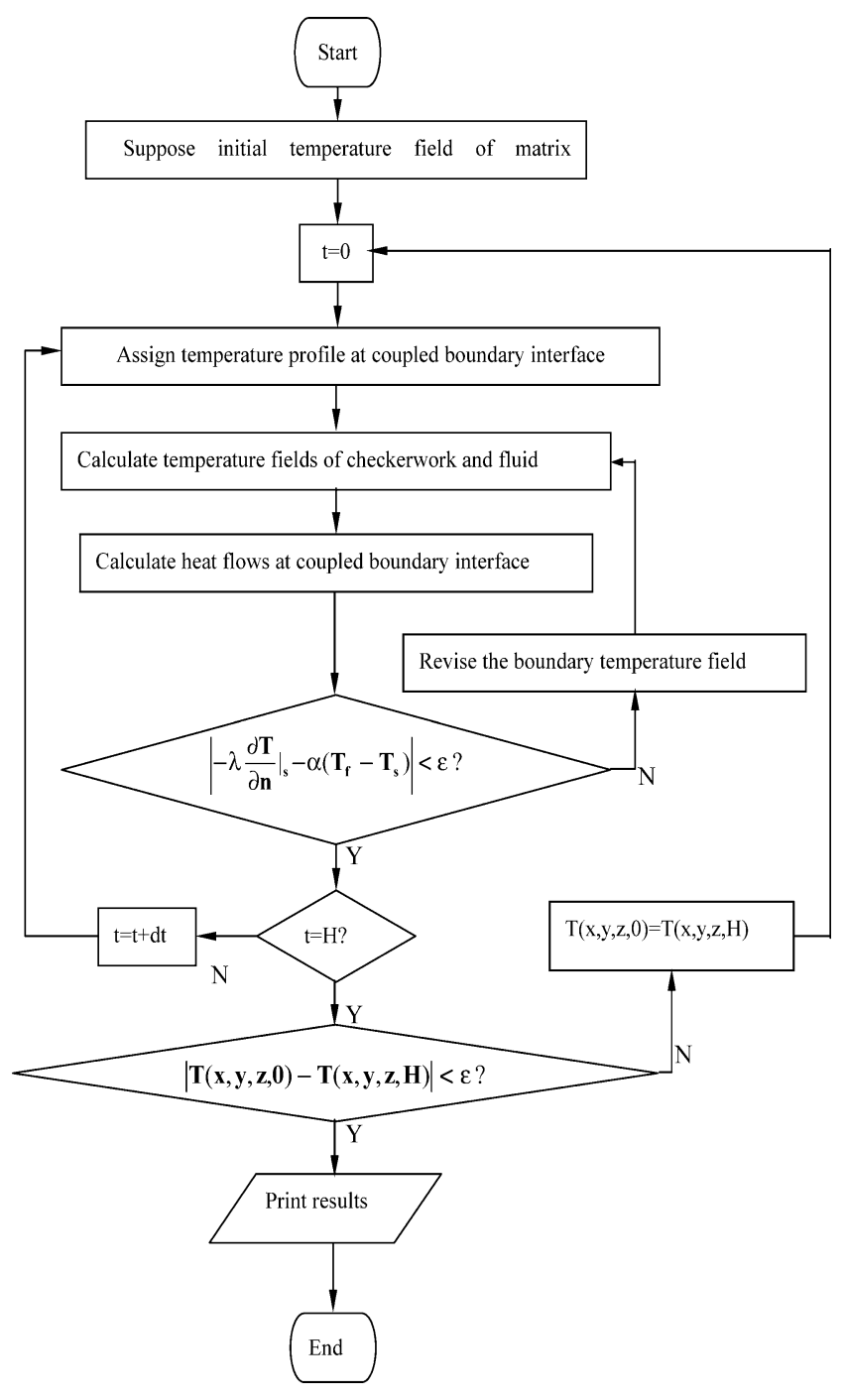

Fig. 2. Procedure of numerical calculation.
(6)). An initial temperature distribution in the checkerwork must be supposed at the beginning of numerical calculation. The numerical calculation was repeated one cycle after a cycle. After a large number of successive iterative calculations, the numerical solution became independent of the initial arbitrary solid temperature profile and the Eq. (6) was satisfied. The procedure of numerical calculation is shown in Fig. 2.

Gauss-Seidel over-relaxation iteration was used to solve the algebraic equations obtained from the heat conduction equation, while Gauss-Seidel under-relaxation was applied to solve the algebraic equations obtained from the heat balance equation of the gas or the blast. When the maximum relative temperature difference between two iterative calculations in the temperature distributions of the checkerwork and the fluid was less than $1.0 \times 10^{-4}$, the temperature distributions could be considered to be convergent.

\section{Results and Discussion}

Numerical simulation was conducted for regenerative chambers of self-preheating hot blast stoves by using the above mathematical model and the numerical method. The height of the chambers is $35.5 \mathrm{~m}$ where the upper silica brick layer is $8 \mathrm{~m}$ high, the middle low-creep high alumina brick layer $8 \mathrm{~m}$ high and common high alumina brick layer $5 \mathrm{~m}$ and the lower clay brick layer $14.5 \mathrm{~m}$ high. Low calorie blast furnace gas flow of $100000 \mathrm{Nm}^{3} / \mathrm{h}$ and $4800 \mathrm{Nm}^{3} / \mathrm{min}$ blast flow rate were used for one stove. The flow rate of combustion air was $70000 \mathrm{Nm}^{3} / \mathrm{h}$. Gas period was $150 \mathrm{~min}$, blast period $80 \mathrm{~min}$ and preheating period $80 \mathrm{~min}$, too. Four stoves were operated in a parallel mode, that is, one stove was in blast period, two in gas period and one in preheating period, as shown in Fig. 3. The variations of temperature with time, measured in this study, at dome of stoves and bottom of checkerwork during one cycle were shown in Fig. 4. The mass flow rate of cold blast passing through a stove was determined from the following equation:

$$
W_{\mathrm{b}}=\rho_{\mathrm{b}}\left(a_{1}+a_{2} t+a_{3} t^{2}\right) \quad \tau_{\mathrm{g}}<t<\tau_{\mathrm{b}}
$$

The coefficients $a_{1}, a_{2}$ and $a_{3}$ in the equation were evaluated by try and error method in order to keep the blast temperature stable and they were equal to $112.249,-0.585$ and $1.934 \times 10^{-3}$, respectively, in this study. At the beginning of blast period, the initial flow rate of blast passing through a

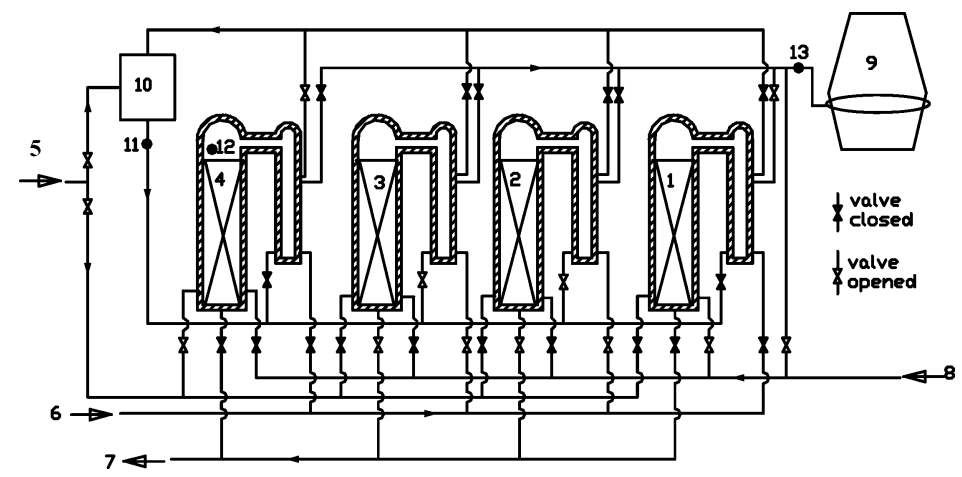

Fig. 3. Schematic of gas flow among four stoves in self-preheating process.

1: stove in blast period; 2, 3: stoves in gas period; 4: stove in pre-heating period; 5: cold combustion air; 6: gas 7: waste gas; 8: cold blast; 9: blast furnace; 10: hot combustion air temperature adjustment room; 11: combustion air pre-heating temperature; 12: dome temperature; 13: mixed blast temperature. 


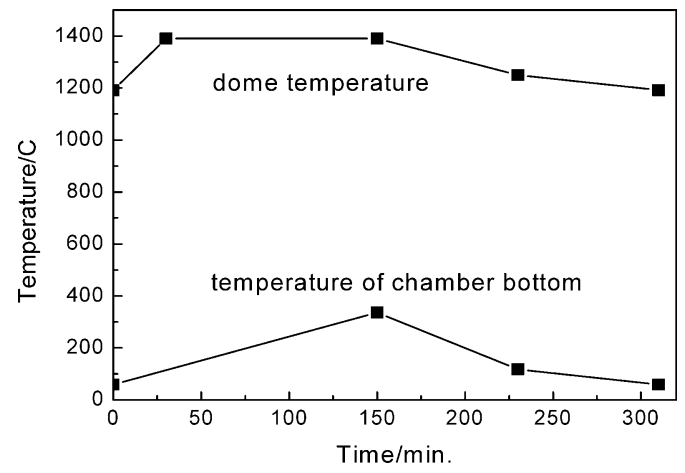

Fig. 4. Variations of temperature with time at dome of stoves and bottom of checkerwork during one cycle.

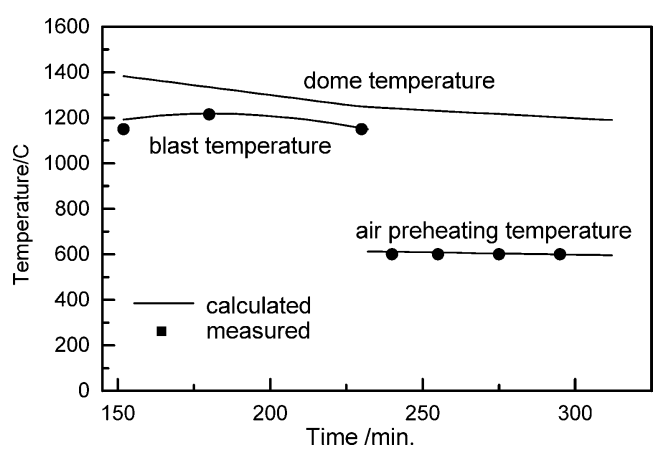

Fig. 5. Dome temperature, mixed blast temperature and combustion air preheating temperature in blast and preheating phases.

stove chamber was $85 \%$ of total flow rate of blast and at the end of blast period $100 \%$ of cold blast passed through the chamber. In preheating period half of the combustion air mass flow rate $\left(W_{\mathrm{a}}\right)$ passed through the chamber. Physical properties of checkerwork in chambers and those of gas and air were chosen from Ref. 7). Mixed blast temperature and combustion air pre-heating temperature were calculated with the following equation obtained from gas heat balance:

$$
T_{\mathrm{f}, \text { mix }}=\frac{W_{\mathrm{i}} T_{\mathrm{f}, \text { out }}(t)+\left(W-W_{\mathrm{i}}\right) T_{\mathrm{f}, \text { in }}}{W}
$$

Dome temperature, mixed blast temperature and combustion air preheating temperature in blast and preheating periods were shown in Fig. 5. The dome temperature curve was used as a boundary condition in blast and preheating periods and the curves of the mixed blast temperature and the combustion air preheating temperature were the results of the numerical calculation. The solid circle points in the figure were the results of measurement. It was shown in Fig. 5 that the blast temperature and air preheating temperature of the numerical calculation agreed well with those of the measurement. The mixed blast temperature was about $1200^{\circ} \mathrm{C}$ and the combustion air preheating temperature about $600^{\circ} \mathrm{C}$.

Variations of temperature of gas and checkerwork surface along the chamber height in gas, blast and preheating periods were given in Figs. 6-8, respectively. It could be seen from these figures that the change in temperature of the checkerwork surface in gas period was the maximum, being about $400^{\circ} \mathrm{C}$, while the variation in temperature of

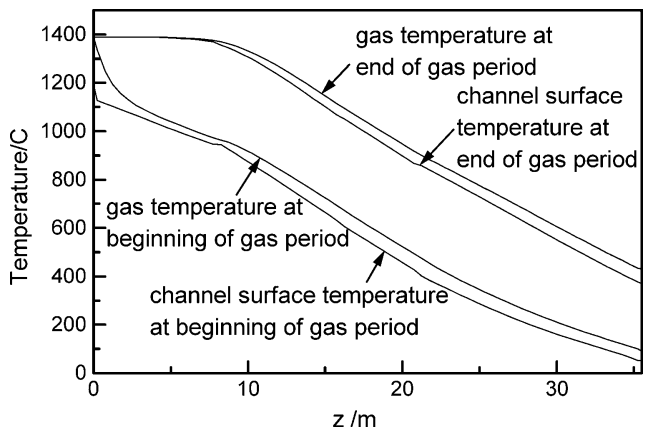

Fig. 6. Variations of temperature of gas and checkerwork surface along the chamber in gas period in self-preheating process.

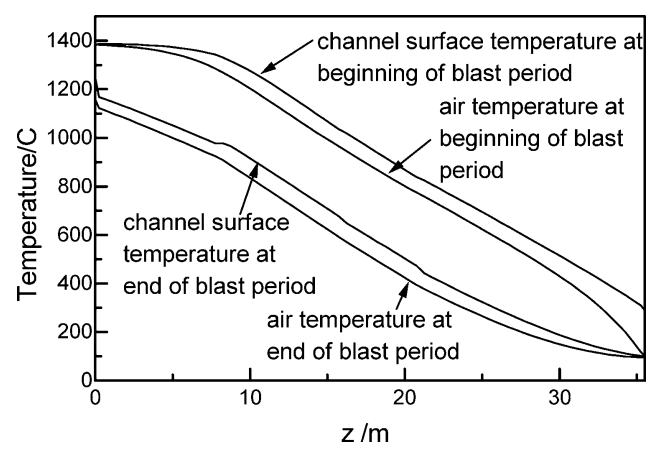

Fig. 7. Variations of temperature of gas and checkerwork surface along the chamber in blast period in self-preheating process.

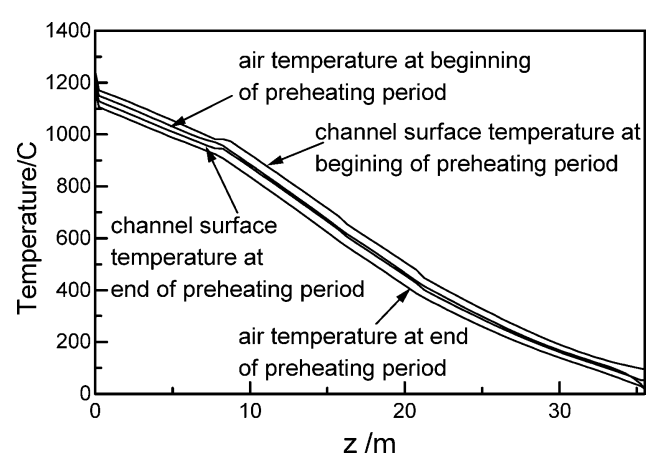

Fig. 8. Variations of temperature of gas and checkerwork surface along the chamber in preheating period in self-preheating process.

the checkerwork surface in preheating period was only 20 $30^{\circ} \mathrm{C}$ due to low flow rate of combustion air passing through the chamber. Attention should be paid to that the variations in temperature of checkerwork surface on gas or blast period were almost the same along the height of the whole chamber.

Figures 9 and 10 showed the variations of temperature of gas, blast and channel surface along height of chamber in gas and blast periods, respectively, in conventional process. Comparing the numerical calculation results in self-preheating process with those in conventional process, it could be known that temperature difference on channel surface from beginning to end of gas period, $\Delta T_{\mathrm{s}}^{\mathrm{g}}$, or blast period, $\Delta T_{\mathrm{s}}^{\mathrm{b}}$, at the same height and temperature difference between channel surface and gas, $\Delta T_{\mathrm{sg}}$, or blast, $\Delta T_{\mathrm{sb}}$, in self-preheating process were larger than those in conventional 


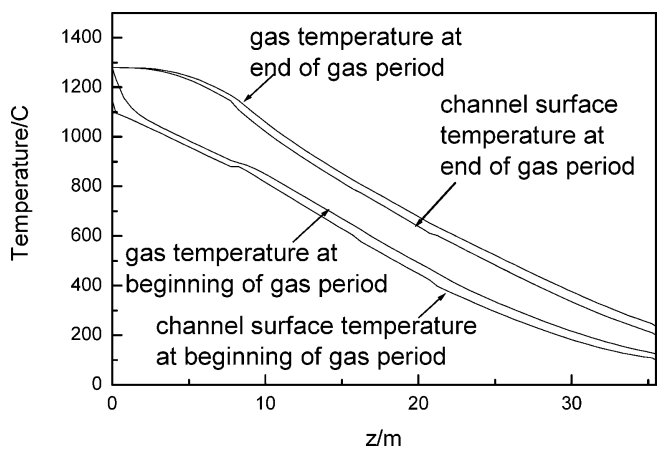

Fig. 9. Variations of temperature of gas and channel surface along the height of chamber in gas period in conventional process.

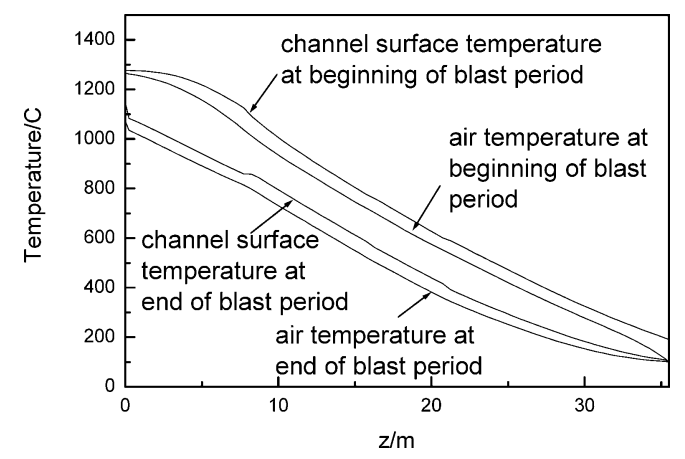

Fig. 10. Variations of temperature of blast and channel surface along the height of chamber in blast period in conventional process.

process. For example, at $z=20.25 \mathrm{~m}, \Delta T_{\mathrm{s}}^{\mathrm{g}}=396^{\circ} \mathrm{C}, \Delta T_{\mathrm{s}}^{\mathrm{b}}=$ $325^{\circ} \mathrm{C}, \Delta T_{\mathrm{sg}}=50^{\circ} \mathrm{C}$ at both beginning and end of gas period, $\Delta T_{\mathrm{sb}}=60^{\circ} \mathrm{C}$ at beginning of blast period and $\Delta T_{\mathrm{sb}}=$ $70^{\circ} \mathrm{C}$ at end of blast period in self-preheating process, but at the same height in conventional process, $\Delta T_{\mathrm{s}}^{\mathrm{g}}$ and $\Delta T_{\mathrm{s}}^{\mathrm{b}}$ were only $182^{\circ} \mathrm{C}, \Delta T_{\mathrm{sg}}=40^{\circ} \mathrm{C}$ at both beginning and end of gas period and $\Delta T_{\mathrm{sb}}=50^{\circ} \mathrm{C}$ at both beginning and end of blast period. In other words, more heat amount can be transfered into and stored in the checkwork during gas period and cold blast can obtain more heat during blast period in self-preheating process than in conventional process, especially in the middle and lower parts of checkerwork.

Because the measurement point of dome temperature (see Fig. 3) was higher than the top of checkerwork, the temperature used as the boundary condition at $z=0$ for the calculation of heat conduction was larger than the real temperature at $z=0$. As a result, the steep temperature gradient near $z=0$ in Figs. 6 -9 was formed. It could be known from these figures that such simplification caused about $30^{\circ} \mathrm{C}$ difference if the temperature was extrapolated to $z=0$ from the numerical results.

Figures. 11 and 12 showed the temperature fields in checkerwork at $z=11.75 \mathrm{~m}$ and at $t=116 \mathrm{~min}$ (in gas period) and $196 \mathrm{~min}$ (in blast period), respectively, in self-preheating process. It was obvious in the figures that the temperature distribution in the checkerwork between two neighbor holes was mathematically paraboloidal. From the numerical calculation results, it was known that the temperature at the center point among three neighbor hole zone reached the maximum in blast or preheating period but the minimum in gas period. The temperature differences be-

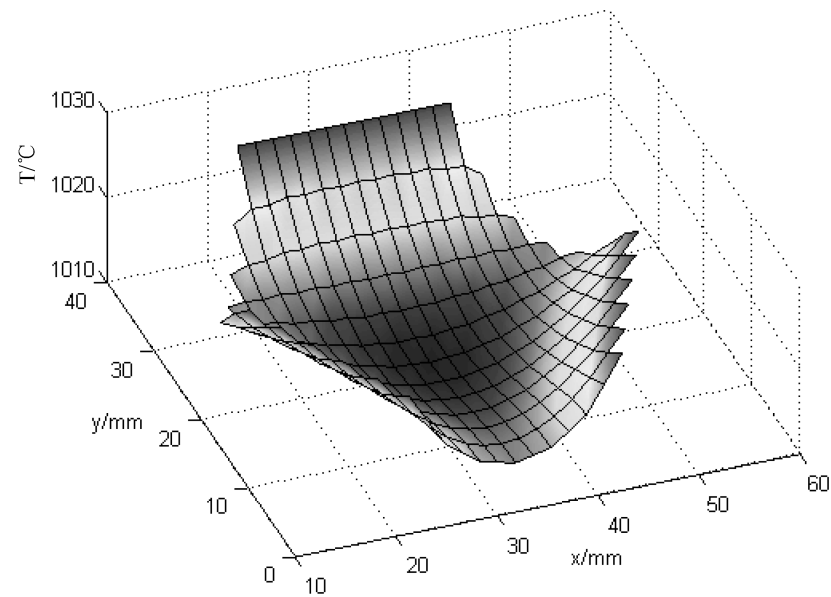

Fig. 11. Temperature field of checkerwork at $z=11.75 \mathrm{~m}$ and $t=116 \mathrm{~min}$. in gas period.

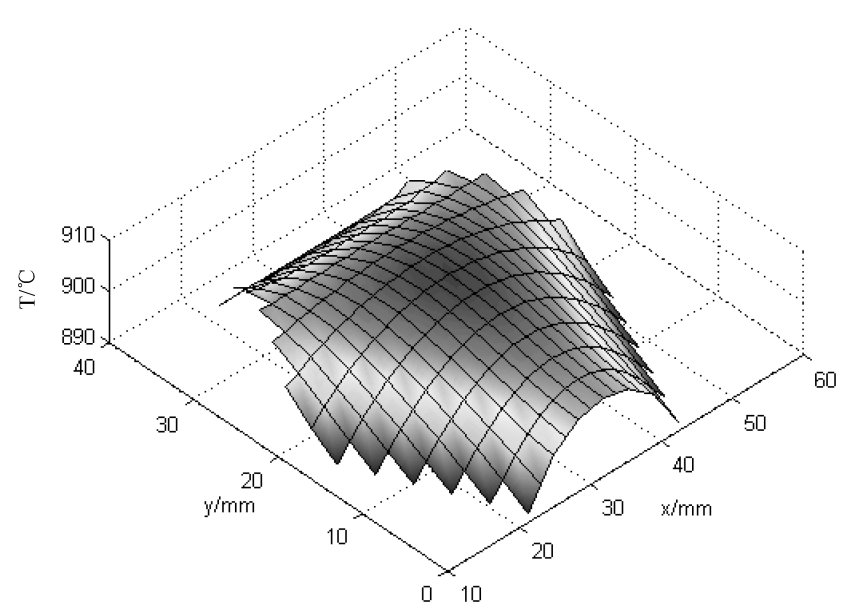

Fig. 12. Temperature field of checkerwork at $z=11.75 \mathrm{~m}$ and $t=196 \mathrm{~min}$. in blast period.

tween the center point and checkerwork surface at $z=11.75 \mathrm{~m}$ were $12^{\circ} \mathrm{C}$ at the end of blast phase, $7^{\circ} \mathrm{C}$ at the end of gas phase and $2^{\circ} \mathrm{C}$ at the end of preheating phase under the conditions used in this study.

\section{Conclusions}

Heat transfer characteristics in regenerative chambers of self-preheating hot blast stoves were studied with numerical simulation method. A three-dimensional unsteady heat conduction equation was used to analyze the heat transfer process in checkerwork of the chamber and was numerically resolved together with the heat exchange between the checkerwork and fluid flowing through the channels in the chambers. The research has revealed the following conclusions:

(1) The results of numerical calculation in this study are in good agreement with those of measurement.

(2) If the combustion air is preheated to $600^{\circ} \mathrm{C}$, mixed blast temperature can reach about $1200^{\circ} \mathrm{C}$ by means of self-preheating process in hot blast stoves with low calorie blast furnace gas.

(3) In comparison with conventional process, more heat amount can be stored and cold blast can obtain more heat in the middle and lower parts of chambers of self-pre- 
heating hot blast stoves. Therefore, the blast temperature can be increased.

(4) The temperature distribution of the checkerwork between two neighbor holes is mathematically parabolic. The temperature differences between the center point of three hole zone and checkerwork surface at $z=11.75 \mathrm{~m}$ were $12^{\circ} \mathrm{C}$ at the end of blast phase, $7^{\circ} \mathrm{C}$ at the end of gas phase and $2^{\circ} \mathrm{C}$ at the end of preheating phase.

\section{Nomenclature}

$A$ : Absorptivity of gas (-)

$C_{0}$ : Radiative coefficient of blackbody $\left(C_{0}=5.67 \mathrm{~W} \mathrm{~m}^{-2} \mathrm{~K}^{-4}\right)$

$C_{\mathrm{p}}: \quad$ Specific heat of checkerwork material $\left(\mathrm{J} / \mathrm{kg}^{\circ} \mathrm{C}\right)$

$C_{\mathrm{P}, \mathrm{f}}:$ Specific heat of fluid $\left(\mathrm{J} / \mathrm{kg}^{\circ} \mathrm{C}\right)$

$H$ : Cycle time of operation of hot blast stoves (s)

$n$ : Normal direction of checkerwork channel surface (m)

$q_{\mathrm{r}}: \quad$ Radiative heat flow rate $\left(\mathrm{J} / \mathrm{m}^{2} \mathrm{~s}\right)$

$t$ : Time (s)

$T$ : Checkerwork temperature $\left({ }^{\circ} \mathrm{C}\right)$

$T_{0}$ : Temperature of regenerator upper surface at $z=0$ $\left({ }^{\circ} \mathrm{C}\right)$

$T_{l}$ : Temperature of regenerator lower surface at $z=l$ $\left({ }^{\circ} \mathrm{C}\right)$

$T_{\mathrm{s}}$ : Temperature of checkerwork channel surface $\left({ }^{\circ} \mathrm{C}\right)$

$T_{\mathrm{f}}$ : Fluid temperature $\left({ }^{\circ} \mathrm{C}\right)$

$T_{\mathrm{f} 0}^{\mathrm{g}}:$ Entrance temperature of gas $\left({ }^{\circ} \mathrm{C}\right)$

$T_{\mathrm{f}, l}^{\mathrm{b}}$ : $\quad$ Entrance temperature of cold blast $\left({ }^{\circ} \mathrm{C}\right)$

$T_{\mathrm{f}, l}^{\mathrm{p}}:$ Entrance temperature of combustion air $\left({ }^{\circ} \mathrm{C}\right)$

$T_{\mathrm{f}, \text { in }}$ : Cold blast or combustion air temperature $\left({ }^{\circ} \mathrm{C}\right)$

$T_{\mathrm{f}, \text { mix }}$ : Mixed blast or preheating temperature $\left({ }^{\circ} \mathrm{C}\right)$

$T_{\mathrm{f} \text {,out }}$ : Temperature of blast or combustion air coming out of chamber $\left({ }^{\circ} \mathrm{C}\right)$

$u_{0}$ : Flowing rate of the fluid passing through the channels at standard state $(\mathrm{m} / \mathrm{s})$
$W_{\mathrm{i}}$ : Mass flow rate of fluid passing through checkerwork $(\mathrm{kg} / \mathrm{s})$

$W$ : Total mass flow rate of fluid $(\mathrm{kg} / \mathrm{s})$

$\alpha$ : Overall heat transfer coefficient $\left(\mathrm{W} / \mathrm{m}^{2}{ }^{\circ} \mathrm{C}\right)$

$\alpha_{\mathrm{c}}$ : Convective heat transfer coefficient $\left(\mathrm{W} / \mathrm{m}^{2}{ }^{\circ} \mathrm{C}\right)$

$\alpha_{\mathrm{r}}$ : Radiative heat transfer coefficient $\left(\mathrm{W} / \mathrm{m}^{2}{ }^{\circ} \mathrm{C}\right)$

$\varepsilon$ : Blackness of gas $(-)$

$\varepsilon_{\mathrm{s}}^{\prime}$ : Effective blackness of the channel surface (-)

$\lambda$ : Thermal conductivity of checkerwork material $\left(\mathrm{W} / \mathrm{m}^{\circ} \mathrm{C}\right)$

$\rho:$ Density of checkerwork material $\left(\mathrm{kg} / \mathrm{m}^{3}\right)$

$\rho_{\mathrm{b}}$ : Density of blast $\left(\mathrm{kg} / \mathrm{m}^{3}\right)$

$\rho_{\mathrm{f}}$ : Density of gas phase $\left(\mathrm{kg} / \mathrm{m}^{3}\right)$

$\tau_{\mathrm{g}}:$ Gas period time (s)

$\tau_{\mathrm{b}}$ : Time from the beginning of gas period to the end of blast period (s)

$\Delta T_{\mathrm{s}}^{\mathrm{g}}$ : Temperature difference on channel surface from beginning to end of gas period $\left({ }^{\circ} \mathrm{C}\right)$

$\Delta T_{\mathrm{s}}^{\mathrm{b}}$ : Temperature difference on channel surface from beginning to end of blast period $\left({ }^{\circ} \mathrm{C}\right)$

$\Delta T_{\text {sg }}$ : Temperature difference between channel surface and gas $\left({ }^{\circ} \mathrm{C}\right)$

$\Delta T_{\mathrm{sb}}$ : Temperature difference between channel surface and blast $\left({ }^{\circ} \mathrm{C}\right)$

\section{REFERENCES}

1) H. Hausen: Z. Angew. Math. Mech., 3 (1929), 173.

2) H. Hausen: Z. Angew. Math. Mech., 2 (1931), 105.

3) P. Butterfield, J. S. Schefield and P. A. Young: J. Iron Steel Inst., 201 (1963), 491.

4) A. J. Willmott: Int. J. Heat Mass Transfer, 7 (1964), 1291.

5) A. J. Willmott: Int. J. Heat Mass Transfer, 11 (1968), 1105.

6) H. H. Bohm: Int. J. Heat Mass Transfer, 6 (1933), 423.

7) Z. Y. Xiang and Q. D. Guou: Regenerative Hot Blast Stoves, Metallurgical Industry Press, Beijing, (1988), 208. 